\title{
El enfoque cualitativo y la renovación de la geografía escolar sustentada en el positivismo pedagógico
}

\author{
The qualitative approach and the renewal of school geography supported \\ by pedagogical positivism
}

\section{A abordagem qualitativa e a renovação da geografia escolar com base no positivismo pedagógico}

\section{José Armando Santiago Rivera}

Universidad de Los Andes

Núcleo Universitario Dr. Pedro Rincón Gutiérrez

jasantiar@yahoo.com, asantia@ula.ve

\begin{abstract}
RESUMEN
El artículo analiza el enfoque cualitativo como opción para renovar la geografía escolar sustentada en el positivismo pedagógico. Desde el siglo XIX, la enseñanza geográfica se facilita con el propósito de transmitir contenidos relacionados con los rasgos físico-naturales del territorio, a partir de la perspectiva descriptiva, reproductora y memorística. Esta realidad educativa es un obstáculo epistémico, pues impide desarrollar la reflexión analítica de las situaciones geográficas comunitarias y de la época. Metodológicamente se revisó bibliografía y exponer una explicación histórica de la geografía escolar desde los fundamentos positivistas y del positivismo a la ciencia cualitativa en la enseñanza geográfica. Concluye al proponer que en la geografía escolar es relevante asumir la opinión originada en el desempeño comunitario del habitante, en el estudio de las temáticas y problemáticas identificadas de su localidad. Aporta la importancia de los testimonios de los habitantes de la comunidad al posibilitar la formación de la conciencia crítica como misión formativa de la geografía escolar.
\end{abstract}

\begin{abstract}
The article analyzes the qualitative approach as an option to renew the school geography based on pedagogical positivism. Since the 19th century, geographical teaching has been facilitated with the purpose of transmitting contents related to the physical-natural features of the territory, from the descriptive, reproductive and memoristic perspective. This educational reality is an epistemic obstacle, as it prevents the analytical reflection of community geographic situations and the era from being developed. Methodologically, literature was reviewed and a historical explanation of school geography from the positivist foundations and positivism to qualitative science in geographical teaching was presented. It concludes by proposing that in the school geography it is relevant to assume the opinion originated in the community's performance of the inhabitant, in the study of the themes and problems identified in their area. It brings the importance of the testimonies of the inhabitants of the community to enable the formation of critical awareness as a formative mission of school geography.
\end{abstract}

Citar como:

Santiago, J. (2020). El enfoque cualitativo y la renovación de la geografía escolar sustentada en el positivismo pedagógico. Espiral, revista de geografías y ciencias sociales, 2(3), 077 - 090. http://dx.doi.org/10.15381/espiral.v2i3.18450 


\section{RESUMO}

O artigo analisa a abordagem qualitativa como opção de renovação da geografia escolar a partir do positivismo pedagógico. Desde o século XIX, o ensino geográfico tem sido facilitado com o propósito de transmitir conteúdos relacionados às características físico-naturais do território, do ponto de vista descritivo, reprodutivo e da memória. Essa realidade educacional é um obstáculo epistêmico, pois impede o desenvolvimento de uma reflexão analítica sobre as situações geográficas da comunidade e do tempo. Metodologicamente, a bibliografia foi revisada e uma explicação histórica da geografia escolar foi apresentada desde os fundamentos positivistas e positivistas até a ciência qualitativa no ensino geográfico. Conclui propondo que na geografia escolar é relevante assumir a opinião originada na atuação comunitária do morador, no estudo das questões e problemas identificados em sua localidade. Contribui para a importância dos testemunhos dos habitantes da comunidade ao possibilitar a formação da consciência crítica como missão formativa da geografia escolar.

PALABRAS CLAVES: Enfoque Cualitativo; Geografía Escolar; Positivismo Pedagógico.

KEYWORDS: Qualitative Approach; School Geography; Pedagogical Positivism.

PALAVRAS-CHAVE: Abordagem Qualitativa; Geografia Escolar; Positivismo Pedagógico.

\section{Introducción}

La época contemporánea presenta una realidad geográfica calificada como complicada, difícil y controversial, debido a lo enrevesado de su comportamiento. Allí, destacan lo evidente de la incertidumbre y los contrasentidos. Igualmente, en la dinámica social es común percibir el sentido y el efecto de la inseguridad, lo inestable, lo ambiguo y lo confuso del mundo globalizado.

En ese contexto, lo geográfico se exhibe con el inoportuno suceder de eventos calificados como desastres naturales, el calentamiento global, el deterioro ambiental y las contradicciones entre la riqueza y la pobreza. A partir de fines del siglo XX, hasta el presente, la explicación de este complicado escenario, se ha realizado principalmente con la perspectiva positivista descriptiva y determinista, a pesar de la existencia de otras opciones paradigmáticas y epistémicas más coherentes con la naturaleza social del objeto de estudio.

En estas condiciones históricas, ha emergido la importancia del testimonio personal de quienes son protagonistas de los sucesos estudiados, al expresar en su lenguaje, la experiencia vivida sobre lo real. Se trata de entender la realidad geográfica al requerir las concepciones, representaciones e imaginarios construidos por sus habitantes. Por ejemplo, ante un problema de la comunidad, acudir a la entrevista y obtener testimonios de los vecinos sobre un acontecimiento geográfico determinado.

Otro acontecimiento relevante en la enseñanza geográfica determinista, naturalista y descriptiva, de origen positivista, es preservar su propósito centrado en caracterizar las condiciones físico-naturales del territorio, como su tarea pedagógica esencial. Aunque teóricamente se propone la explicación geográfica, Al considerar el interés de la experiencia de los ciudadanos, en especial, sus analíticos puntos de vista sobre la realidad, el mundo y la vida.

De allí el interés por considerar los planteamientos de docentes investigadores que a fines del siglo XX e inicios del nuevo milenio, ofrecieron contribuciones significativas sobre la notable influencia del positivismo en las condiciones del momento histórico, la finalidad educativa y su influencia en la geografía escolar. Por tanto, citar sus planeamientos va en la dirección de la insistencia en el cuestionamiento sobre el apremio de revisar la influencia del positivismo como la exclusividad para construir el conocimiento. 
Así, se rompió con la objetividad revelada por el resultado, la resistencia al cambio, la reproducción, la acumulación conceptual y la verdad absoluta, entre otros aspectos. Esta problemática motivó convocar al enfoque cualitativo como opción para renovar al positivismo pedagógico en la geografía escolar. Al respecto, en primer lugar, analizar la explicación histórica de la geografía escolar desde los fundamentos positivistas y, en segundo lugar, razonar del positivismo a la ciencia cualitativa en la enseñanza geográfica.

Metodológicamente, se realizó la investigación documental con el propósito de obtener los fundamentos requeridos y organizar un planteamiento sobre el privilegio exclusivista del positivismo y el advenimiento de las opciones del enfoque cualitativo. El resultado ha sido contribuir con la innovación de la orientación pedagógica tradicional de la geografía en la escuela, con conocimientos y prácticas renovadas, acordes con las necesidades de la sociedad contemporánea hacia la formación educativa humanizadora como reto histórico.

\section{La explicación histórica de la geografía escolar desde los fundamentos positivistas}

La originalidad de la versión positivista en el conocer la realidad como constructo social, derivó de los aportes facilitados por Bacon, Galileo, Descartes y Newton, entre otros. De sus apreciaciones sobre lo real y cómo se elaboran las concepciones sobre lo auténtico, lo probado, verdadero e indiscutible, obedeció a los cuestionamientos sobre la verdad concebida desde la perspectiva religiosa poco confiable por estar impregnada de la poca certeza de la existencia divina (Santana, 2005).

Eso es determinante considerar cuando se desarrolla la explicación del cambio paradigmático y epistemológico del mundo contemporáneo, acudir a los acontecimientos de los siglos XVIII y XIX. El motivo es la manifestación de la controversia entre la especulación metafísica del medioevo y el surgimiento de las razones sustentadoras del positivismo. Allí, los temas del debate fueron la convicción de la verdad divina y la verdad objetiva de la realidad, el mundo y la vida (Martínez, 2016).

Las críticas revelaron la decadencia de la verdad derivada del privilegio religioso, al ser afectada por la renovación filosófica, la ruptura religiosa protestante en el catolicismo, la consolidación de los fundamentos de la ciencia positivista, entre eventos reveladores de otros cambios de la época. En esas condiciones históricas develaron la crisis de las explicaciones divinas con el desaliento sobre la certidumbre sustentada en el testimonio celestial y la fe, como lo establecido como la verdad (Martínez, 2004).

La decadencia se apreció al consolidarse rasgos sustentadores de otra veracidad; por ejemplo, para conocer fue imprescindible el experimento, validar la certeza de lo concreto, lo innegable y lo cierto e igualmente, apreciar la realidad en su existencia inobjetable, inequívoca e irrefutable. Así, lo real es y existe en condición de objetivo e irrefutable. Eso tradujo evitar las distorsiones religiosas idealizadas e inmateriales y dar paso a la existencia visible, práctica, cierta, auténtica y evidente de lo real.

Este cambio colocó en el primer plano a la visión mecánica fundada por Newton, quien propuso que la construcción del conocimiento debe realizarse con sentido perdurable y absoluto. Por tanto, elaborado en el desenvolvimiento de eventos empíricos diseñados para objetivamente reproducir la realidad, con procesos confiables, válidos y aceptados por la comunidad científica, con condiciones de neutralidad, apoliticismo y desideologización. Al respecto, en el ámbito social, en palabras de Graffe (1990):

La visión del mundo y de la realidad empiezan a cambiar con las teorías de Einstein sobre la relatividad y la física cuántica que cuestiona la concepción tradicional de la materia 
como algo estable, se pone en tela de juicio la noción de objetividad y se introduce al observador como parte del experimento ( $p .58)$.

En esta perspectiva, en el caso de la geografía, lo real es lo concreto. De esta manera, los eventos derivados de la relación de la sociedad y la naturaleza, demandaron valorar su desenvolvimiento de hecho existente, perceptible, fidedigno y verídico, a partir de su localización, causalidad, sistematicidad y generalización, tal como fue planteado por Alejandro de Humboldt. Eso aseguró a la disciplina geográfica el rigor, la firmeza y la solidez científica (Capel, 1988).

Del campo del conocimiento de la cultura general, dio el salto epistémico concebida como opción acertada y válida en el análisis de los problemas ambientales, geográficos y sociales, a partir del siglo XIX. Con eso, la episteme positivista, testificó ser garante de la validez y la confiablidad de la verdad objetiva, imparcial y prueba demostrativa de lo innegable, lo cierto y lo indiscutible. Así, asumió el cambio epistemológico de la descripción de lo real a su explicación inductiva y deductiva (Calvo, 2009).

En relación con este acontecimiento, Mabel (2007), afirmó que el positivismo se forjó como orientación de la ciencia, a partir de posibilitar la explicación de las situaciones geográficas, a partir del desciframiento de los mecanismos naturales como garantía de verdad. Así, el acento paradigmático se originó al concebir lo verdadero obtenido del análisis simplificador de sus partes constitutivas, en tantas partes como fuese posible; es decir, la fragmentación de la situación geográfica.

En efecto, los objetos de estudio se limitaron a conocer las potencialidades de la naturaleza; en especial, identificar sus recursos concebidos como materias primas, dado el impulso de la revolución industrial, el creciente mercado, no solo europeo, sino también hacia las colonias allende el atlántico. Con esta opción, el capital realizó la acción exploratoria en diversas regiones de Europa occidental y en el continente americano, en principio, por las Sociedades Geográficas y luego por las empresas capitalistas.

El contacto inicial con lo natural estuvo centrado en simplemente describir los rasgos de la superficie terrestre, con la observación-narración de sus características. Es entonces una visión, de enumeración, clasificación y puntualización de la fisonomía de los territorios. Históricamente, en el siglo XX, Plans (1962), opinó que esta labor es: “...más bien descriptiva, nunca explicativa, pero capaz de proporcionar una imagen simple de la tierra y de los fenómenos físicos y humanos que en ella tienen lugar" (p. 20).

Al contactar con los territorios dispersos en la superficie terrestre, la descripción dio paso a la versión explicativa planteada por Humboldt, ante la diversidad, multiplicidad y particularidades territoriales. Por tanto ya no fue tan solo describir, porque la formulación de preguntas ante lo observado, forzó la búsqueda de respuestas y el incentivo de la interpretación analítica, cuya gestión produjo la apropiación de los territorios en la tarea por apoderarse de sus recursos naturales, ante la necesidad demandante del impulso industrial.

El aprovechamiento de la naturaleza demandó analizar los territorios con los principios humboldtiano y facilitar el aprovechamiento de sus potencialidades. De allí la iniciativa de descifrar a partir del estudio analítico-interpretativo de los territorios, con fines de conocer sus sistemas, identificar recursos y las facilidades de su explotación y beneficios. Esta tarea tuvo en los fundamentos del positivismo, la aplicabilidad de los aportes de reconocidos científicos. Tal es son los casos citados por Dobson (1997), de la manera siguiente:

...Bacon quien se apoyó en métodos que para la ciencia implicaban el dominio y control de la naturaleza; Descartes insistió en que incluso el mundo orgánico era simplemente una extensión de la naturaleza mecánica general del universo; y Newton sostuvo que las 
operaciones de este universo-maquina se podían entender reduciéndolo a una colección de partículas movibles, impenetrables, duras, macizas, sólidas (p. 62).

Estas contribuciones epistémicas confirmaron la validez del positivismo, como la opción sustentada en la aplicación del mecanicismo, la funcionalidad, la linealidad y la fragmentación. Con estas tareas fundamentales, se pudo asegurar en la construcción del conocimiento la imparcialidad, la neutralidad, el rigor, el apoliticismo. Además, la exigencia de estudiar los objeto de estudio, sin interferir con juicios de valor, debido a su efecto distorsionador (Gallego y Miranda, 2003).

Precisamente, esta orientación didáctica facilitó el afinamiento de la explicación de los procesos derivado de concebir lo científico con la funcionalidad y el mecanicismo hacia la formulación del conocimiento válido y cierto. Al reflexionar sobre esta circunstancia Martínez (2004), resaltó que esta forma de conocer tradujo la exigencia de la aplicación de métodos, técnicas y procedimientos justos, ecuánimes, despolitizados y desideologizados, aplicados con sentido juicioso, rígido, estricto y riguroso.

Otro fundamento afianzado y arraigado en la perspectiva científica positiva fue su acento infalible, ineludible y certero. Indudablemente con estos planteamientos teóricos y metodologías, aseguró la validez del conocer y la confiablidad social de lo cierto, lo innegable e incuestionable. Esto lo justifica Camilloni (2001), quien distinguió la importancia adquirida por el positivismo fundado en la severidad, la seguridad y la ecuanimidad, como garantías del conocimiento concebido como verdad científica absoluta.

A fines del siglo XX, el desarrollo de la ciencia y la tecnología contó con el paradigma y los conocimientos y prácticas del positivismo. Aunque mejoró para asegurar la verdad científica con el análisis de los hechos, a partir de la observación neutral y el desarrollo de experiencias controladas. El resultado, la conformación de protocolos aseguradores de la capacidad de obtener resultados altamente favorables hacia el bienestar, el progreso y el adelanto científico (De Zubiría, 2006).

Con el paradigma positivista, se organizó la acción educativa a partir de cumplir la tarea formativa centrada en contenidos, transmitidos como fragmentos en los procesos de enseñanza y de aprendizaje. Desde estos fundamentos, la educación asumió la tarea de transferir nociones y conceptos de acento enciclopédico, como opción dedicada a aportar el bagaje cultural de las generaciones pasadas, a la actual generación y aspirar al logro de la finalidad educativa de desarrollar la capacidad intelectual de los educandos (Mejía, 2011).

La educación emergió de la necesidad de culturizar a la población, considerada como tarea de la burguesía, se impuso superar el pronunciado analfabetismo. El interés fue ofrecer un espacio propicio para facilitar la lectura, la escritura y las operaciones matemáticas elementales. Las élites adoctrinadas por las lecciones de los doctos antiguos, al crear la escuela, consideraron la educación, como la opción garante del acceso a la cultura, heredada desde la antigüedad hasta la época moderna.

Eso significó potenciar al culto a la inteligencia forjada desde el aprendizaje reducido a la repetición del enciclopedismo teórico, cedido por el educador con acciones didácticas, como el dictado y la explicación. Es la acción pedagógica apegada a la exclusividad de la transmisión de información, como base esencial del propósito de educar ciudadanos con la obtención de abundantes datos sobre los diversos ámbitos del conocimiento, con la enseñanza de acento directivo, memorístico y centrado en el aula (Aiello, 2005).

Este acontecimiento tuvo notables efectos en la formación educativa de los ciudadanos, en el siglo XIX y luego, en el siglo $\mathrm{XX}$, sostenido, en principio, en la tradicional 
descripción geográfica y a continuación, en el conductismo pedagógico. En ambas iniciativas, guiar el acto educante hacia la transmisión contenidos programáticos de acento absoluto y categórico, estructurados por los expertos, con el propósito que sean facilitados a los estudiantes, para ser reproducidos y memorizados como revelación de aprendizaje (Santiago. 2016).

Así, educar exige utilizar rigurosas pautas conceptuales y metodológicas para enseñar y aprender, a la vez que verificar lo aprendido en la práctica escolar cotidiana, con el uso de pruebas objetivas, elaboradas bajo el formato del test psicológico y asegurar la eficacia e importancia formativa del acto educante. Es verificar el logro del aprendizaje mediante la cuantificación ofrecida por el uso de la estadística, base de la evaluación sumativa.

Esta labor pedagógica, de acuerdo con Aiello (2005), permanece desenvuelta en una actividad pedagógica y didáctica centrada en el educador, quien proporciona el conocimiento que deben saber los educandos; en la generalidad de los casos, obtenido en el libro concebido como el recurso didáctico fundamental, pues contiene los contenidos a enseñar, como también caracterizado por su sentido imparcial, absoluto e inmutable, elaborado por los investigadores. Se trata de la lección antigua.

En la perspectiva de Santana (2005), de esta forma se promovió la enseñanza, con la aplicación de un método estricto, sustentado en la experimentación controlada, registrada y estrictamente fiscalizada. Esta acción para ser válida y confiable, se afincó en lo cierto con lo preciso del método y la convalidación del número. Así, se pudo asegurar que los acontecimientos suceden independientemente de los sentidos y el conocer implica objetivizar lo observado.

Con este planteamiento, el conocimiento científico geográfico comenzó a ser facilitado en el aula de clase con la observación, como la direccionalidad promotora del entendimiento de las temáticas y problemáticas geográficas, en sus causas originales y sus respectivos efectos. De esta forma, el propósito epistemológico se orientó hacia el logro y aseguramiento de la objetividad emanada del contacto directo argumentado en la convicción apoyada en percibir y reproducir lo observado con exactitud (Perafán, 2004).

Eso determinó que el objeto de estudio fueron las características físico-naturales del territorio, por ser lo más objetivo de la realidad geográfica. Así, con los aportes del positivismo la geografía escolar fue desarrollada en la explicación de las diversas regiones del planeta y el interés pedagógico y didáctico fue entender la naturaleza de la comunidad; en especial, reproducir paisajes reveladores de las condiciones propias del lugar, como base de la pretendida calidad formativa de la enseñanza geográfica.

Es preocupante que esta situación pedagógica y didáctica, originada a fines del siglo XVIII, con la fundación de la escuela, se ha convertido en la tarea básica de enseñar geografía en el aula de clase. Se trata de la actividad formativa circunscrita a desarrollar la memorización de nociones y conceptos, en una tenaz competencia entre los estudiantes para obtener alta calificación, en la mayoría de las veces, sin ejercer el dominio de los contenidos programáticos (Santiago, 2013).

Indiscutiblemente, la enseñanza de la geografía orientó sus procesos pedagógicos y didácticos hacia la reproducción literal, veraz y rigurosa de los aspectos del territorio establecidos como contenidos programáticos, y enseñados a través del dibujo, la copia, el calcado y el dictado. De esta forma, la enseñanza geográfica se instituyó como la actividad formativa esencial del acto educante, con la transcripción del libro al cuaderno, pues tan solo enseñó los caracteres territoriales, representados en grabados pictóricos. 
La acción pedagógica reproductora de contenidos programáticos en las asignaturas geográficas, significó en el punto de vista de Finocchio, García, Iaies y Segal (1998): “...considerar que el mundo está constituido por aquello que puede ser percibirse, observarse, que no existe nada más allá de los fenómenos captados por los sentidos" (p. 55). Así, se hizo común preservar en la formación educativa la objetividad como una de sus exigencias más fundamentales de la garantía académica de la geografía como disciplina.

Ese aprendizaje contraviene las exigencias de la formación educativa ante la complicada realidad del inicio del nuevo milenio, porque se centra en promover procesos formativos afectos a concepción de la geografía descriptiva y el apego de la pedagogía y la didáctica del siglo XIX. Lo criticable es educar geográficamente a los ciudadanos con la enumeración de detalles físico-naturales de la naturaleza. De esta forma se marca distancia de las necesidades sociales e impide entender la complejidad del mundo contemporáneo.

Es un circuito educativo descrito en la década de los años cincuenta del siglo XX por Ferriere (1959) de la manera siguiente: “...el alumno aprende lo que quiere decir que trata de memorizar la mayor o menor cantidad de materia para recitarla en la lección siguiente y en el examen que cerrará el año escolar" (p. 65). Lo inquietante es percibir todavía este desempeño rutinario en la práctica escolar cotidiana, a pesar de las innovaciones educativas, pedagógicas, didácticas y geográficas del mundo contemporáneo.

En base a los aspectos enunciados, el positivismo ha cumplido una excelente función formativa que no se puede desconocer. Su efecto pedagógico y didáctico ha educado generaciones de ciudadanos al transmitir el conocimiento geográfico en los espacios escolares. El resultado, la formación de letrados, intelectuales con excelente dominio conceptual, obtenido en la lectura bibliográfica y expuesta en forma disciplinada, pasiva, receptora y espectadora de los estudiantes, pero sin la aplicabilidad reflexiva y crítica (Calle, 2012).

\section{Del positivismo a la ciencia cualitativa en la enseñanza geográfica}

El escenario sociohistórico en que se ha desarrollado el quiebre epistémico del positivismo y la emergencia del enfoque cualitativo, se manifiesta como una realidad, caracterizada por un comportamiento, cuya explicación exige opciones paradigmáticas y epistemológicas propias, adecuadas y coherentes con su complicado suceder, de acento turbulento y acentuadamente innovador y creativo. Allí, lo enrevesado de sus acontecimientos genera considerables repercusiones en la sociedad mundial.

Por ejemplo, la época impregnada del sentido del tiempo acelerado, la vivencia de la incertidumbre, la paradoja y el contrasentido, la revelación de la complejidad mostrada con los rasgos del relativismo, la inestabilidad, la debilidad y la fragilidad epistémica. Estos hechos han dado origen a aspectos reveladores impedimentos que han fraguado dificultades para promover la construcción del conocimiento sostenido la convicción de la rigidez del mecanismo, la certeza y lo riguroso (Rivera y Cárdenas, 2004).

Por el contrario, ha reivindicado nuevas perspectivas epistemológicas en la dirección de realizar la interpretación de los acontecimientos a partir de las siguientes perspectivas: la objetividad se origina en la subjetividad de sus actores, la acumulación del conocimiento ha sido sustituida por la transformación conceptual y la observación contemplativa de los sucesos, ha exigido involucrarse en el objeto de estudio. Estos cambios han mostrado la ruptura con el paradigma cuantitativo-exacto-matemáticológico e hipotético-deductivo. 
En la ciencia geográfica, en los planteamientos de Santos (2004), se apreció que en las condiciones de la época, las investigaciones de esta disciplina, además de descriptivas, cuantitativas y de la percepción, también fueron fomentadas en los ámbitos de la geografía radical, humanística, cultural y fenomenológica. En efecto, construir el conocimiento, significó recurrir a los fundamentos del enfoque cualitativointerpretativo-naturalista-flexible-reacomodable.

Por tanto, el conocimiento geográfico también puede ser construido con lo manifestado en los testimonios personales de acento provisional, falible, transitorio y perecedero, al mismo tiempo humanamente contaminado. En esta innovación, los atributos y rasgos de la vulgaridad, antes descalificados por la ciencia positiva por ser poco válidos y confiables, han sido considerados como una excelente contribución para entender la realidad geográfica, en la perspectiva personal de sus habitantes (Santiago, 2012).

Lo vulgar mostrado en los testimonios revelados por los ciudadanos como constructos empíricos sobre la realidad geográfica vivida, han servido para ver lo real con otras posibilidades perceptivas referidas al punto de vista de sus protagonistas. El propósito ha sido aportar planteamientos que facilitan descifrar las internalidades evadidas por la objetividad positivista. En esa dirección, se reivindica el sentido común y la intuición y asegurar la validez del testimonio personal emitido. Así, de acuerdo con Hernández (1996):

Siendo pensantes, elaboramos el mundo que nos rodea, tal como lo haría cualquier otro ser viviente. La ciencia vuelve la mirada hacia el sentido común. La realidad no se puede tratar como suma de elementos pues dado que tiene información del todo... y es imposible ser neutral (p. 23).

Deesta manera, la ciencia geográfica tuvo la oportunidad de desarrollar la investigación sobre sus temáticas y problemáticas en forma acorde, coherente y pertinente con la situación asumida como objeto de estudio. Ahora la geografía no se limita a un solo paradigma y epistemología, como ha sido tradicional, sino que asume lo estudiado con un método ajustado a su desenvolvimiento como problema, cuya explicación de los sucesos, implica ser analizados en el ámbito de cambios vertiginosos y tendencias impredecibles.

Esto ocurre a fines del siglo XX e inicio del nuevo siglo, para determinar que el positivismo ya no es la única opción epistémica para elaborar el conocimiento científico, pues se ha valorado la importancia de la apreciación subjetiva de la realidad, en la opinión de las personas, entre otros aspectos. Según Inga (2009), el cambio es que el conocimiento de lo real, también se puede construir con los puntos de vista evidenciados desde la subjetividad de sus protagonistas.

Para la geografía escolar y su enseñanza, esta novedad epistémica favorece la oportunidad de diversificar la acción pedagógica y didáctica e innovar sus procesos formativos. Es entonces; por ejemplo, una opción en la dirección de aplicar los contenidos programáticos con estrategias de enseñanza centradas en la investigación. De esta forma, el contenido geográfico escolar se puede problematizar e indagar su existencia y transformación, a partir de la consulta de los habitantes involucrados en lo estudiado.

Significa para la geografía escolar promover el acercamiento vivencial del investigador en la problemática investigada; aspecto reivindicado por Rivera y Cárdenas (2004), para quienes los desafíos que enfrenta la formación del ciudadano del siglo XXI, deben ser acometidos con una orientación pedagógica fortalecedora de la conciencia crítica, estimulada en la búsqueda, procesamiento y elaboración del conocimiento, en la tarea de entender la realidad vivida; es decir, promover la investigación. 
Este planteamiento determina considerar que una opción para promover la generación del conocimiento en la práctica escolar cotidiana de la enseñanza geográfica, se pueden aplicar los enfoques propuestos por la orientación cualitativa en las ciencias sociales (Santiago, 2013). Por tanto, el acto educante debe revisar las formas de explicar la complejidad del mundo vivido, y obtener en el aula, el conocimiento coherente con la comprensión de los acontecimientos complicados que vive en la comunidad, con el apoyo empírico de sus habitantes.

Se trata de un cambio significativo en la posibilidad que los habitantes de la comunidad, puedan explicar sus propias realidades, a partir de sus representaciones, concepciones e imaginarios. Eso trae como consecuencia, no facilitar la transmisión de contenidos programáticos, sino a través de la formulación de preguntas al respecto, los estudiantes puedan realizar investigaciones que faciliten conocer de manera directa, aprender significativamente y echar las bases de la conciencia crítica (Villegas, 2001).

La forma de conocer desde los planteamientos de las personas, significa en palabras de Martínez (1999), asumir el objeto de la enseñanza geográfica entendido desde las representaciones de quien lo vive; de la forma como el observador influye en lo observado; de la observación a partir lo que se conoce, entre otros aspectos. Así se supera la actitud contemplativa neutral y apolítica de la realidad, para privilegiar el protagonismo personal en el acto del conocer y fortalecer la acción indagadora.

Entonces la enseñanza de la geografía reivindica los saberes empíricos, naturales y espontáneos, de los individuos y su protagonismo en sus prácticas geográficas cotidianas. De esta forma, se hace posible desarrollar explicaciones y descifrar desde una racionalidad abierta al diálogo en la realidad habitual. Es la orientación cualitativa que rescata el sentido común, la intuición y la experiencia, curtidos en el desempeño ciudadano del habitante de la comunidad.

En la construcción del conocimiento geográfico, se presenta la valiosa oportunidad de valorizar las lecturas empíricas de las personas sobre su propia realidad. En este sentido, al analizar este planteamiento Mabel (2007), resaltaron el hecho de asumir científicamente la realidad; traducir la iniciativa de reivindicar la opción de escuchar de viva voz a los actores, quienes pueden exponer sus constructos elaborados con su epistemología de la calle y el desempeño ciudadano, en su mundo inmediato.

Enseñar geografía en la escuela, desde lo expuesto, traduce la ruptura con las ataduras del aula de clase para ir al entorno inmediato, a consultar la opinión sobre las concepciones elaboradas por los ciudadanos sobre los temas y problemáticas ambientales, geográficas y sociales. Es rescatar la opinión personal para analizar las circunstancias vividas. Por tanto, el hecho de visibilizar las razones asumidas por los habitantes, implican ver lo real, desde la diversidad democrática (Inga, 2009).

Ahora es posible agitar la dialogicidad comunitaria, reivindicada como base de la renovada episteme que interpreta la realidad geográfica con las representaciones sociales de acento empírico, práctico y habitual, pero con un notable sentido social, originado en la vivencia y convivencia comunitaria. Desde esta perspectiva, elaborar el conocimiento implica el apoyo del uso del lenguaje, como medio para comunicarse abiertamente con sus semejantes en el escenario natural y espontáneo de la vida diaria.

Es la geografía vivida revelada en la expresión de lo que piensa el común, tradicionalmente concebido como portavoz del saber vulgar. Es la realidad interpretada en el diálogo entre quienes lo construyen en su accionar colectivo y personal del habitante de la localidad. Eso asegura para la enseñanza geográfica, la posibilidad pedagógica y didáctica de debatir la teoría de los problemas en el aula 
y consultar luego las concepciones elaboradas por las personas al respecto, en la dinámica comunitaria (Santiago, 2016).

Indiscutiblemente que de allí derivará un nuevo conocer producto de esta innovadora vía explicativa de lo real. El lenguaje permite desarrollar la renovadora hermenéutica que, al triangularse con las revelaciones personales y los planteamientos teóricos de los expertos, se facilita comprender la explicación social plural y diversa. Ahora, en la exposición verbal expuesta por los propios actores, se facilitará la gestión pedagógica para reconstruir la realidad que existe en la mente colectiva.

La dialogicidad potencia la posibilidad de las personas para observar, describir, explicar y evaluar desde sus puntos de vista la realidad vivida. Epistemológicamente, implica considerar la realidad geográfica en las concepciones, representaciones e imaginarios de sus habitantes. Por tanto, para la práctica escolar cotidiana, hay la posibilidad de conversar con los actores que la protagonizan, a la vez poder descifrar las explicaciones elaboradas desde sus actuaciones y saberes obtenidos en condición de ciudadanos (Calvo, 2009).

Así el docente participa activamente en las prácticas sociales y en la reconstrucción de lo real. Esta posibilidad le permite involucrar a su práctica escolar en descubrimiento o redescubrimiento de la situación de la institución educativa y de su integración con la comunidad, pero en condición de actora analítica e interpretativa de los acontecimientos ambientales, geográficos y comunitarios.

Al analizar esta situación, Ríos (2004), expuso que la importancia de considerar las acciones realizadas por los docentes y los estudiantes en los escenarios escolares, además qué piensa y opinan sobre los temas de su actividad educativa; en especial, sobre la geografía de su comunidad. Es la posibilidad de reivindicar su desempeño y experiencia sobre la finalidad educativa, el currículo, como del desarrollo de los procesos de enseñanza y de aprendizaje en que actúa y forja su experiencia sobre el acto educante.

A fin del siglo XX, cuando el cambio histórico fue evidente, al analizar la elaboración del conocimiento, Martínez (2009), destacó la relevancia obtenida por la renovación paradigmática y epistemológica, al facilitar comprender el desenvolvimiento de la acción educativa en el pensamiento y voz de los educadores y de sus estudiantes; también mejorar la capacidad de pensar en forma abierta y flexible, como desplegar ejercicios pedagógicos para resolver problemas críticamente, al estudiar los problemas comunitarios y del aula.

Al iniciarse el nuevo milenio, es común la exigencia de aprender a involucrarse en la comunidad, comunicar, discutir, razonar e indagar nuevos conocimientos, desde una acción pedagógica y didáctica potenciadora de la lectura, la escritura, la reflexión, la criticidad y la creatividad. Es otra oportunidad para educarse a partir el entendimiento de la realidad vivida. Significa que aunque todavía persiste la transmisión de contenidos programáticos, existe la posibilidad cierta para descifrar lo real en las perspectivas personales.

Esta epistemología, para Villegas (2001), ha facilitado avanzar más allá de la simple contemplación de lo real, pues la verdad es un conocimiento construido al interpretar el contexto ambiental, geográfico y social. Eso supone colocar en el primer plano a la importancia de las concepciones del mundo, la realidad y la vida de sujetos históricos, reflexivos y analíticos. Ahora es posible que ellos puedan tomar decisiones, emitir juicios y desarrollar comportamientos democráticos, con sus propias creencias.

La apertura epistémica, en el punto de vista de Perafán (2004), traduce lo valorable de asumir la experiencia directa, el significado del mundo de la vida diaria y los aprendizajes empíricos obtenidos en la vida cotidiana. Allí, lo relevante es colocar 
en el primer plano los saberes personales fundados en conocimientos, experiencias y prácticas desenvueltos en las vivencias, costumbres y rutinas ocurridas en su entorno. Así se comienza a prestar atención al desafío de renovar la práctica escolar cotidiana de la geografía escolar.

Un motivo lo constituye que se ha colocado en el primer plano a los significados de los educadores y de sus estudiantes sobre las situaciones del aula, la escuela y la comunidad, como punto de partida de la interpretación de lo real. Este es el escenario en que se conjugan los puntos de vista de los docentes, estudiantes y habitantes, involucrados en un proceso de acción-reflexión-acción, pues facilita desarrollar la capacidad interpretativa de los sucesos, en la práctica pedagógica.

El logro formativo es construir el conocimiento en forma metódica, sistemática y ordenada, en un proceso también riguroso, estricto y juicioso, desenvuelto en una actividad hermenéutica, activa, crítica, creativa y liberadora. Es educar al ciudadano democrático. La geografía escolar, desde esta perspectiva, debe considerar que el conocimiento no está elaborado y es imprescindible facilitar estrategias didácticas orientadas a procesar su construcción en forma deliberante y critica (Mejía, 2011).

El cambio repentino, incierto y acelerado de los sucesos, inciden en revisar el tratamiento pedagógico y didáctico de la enseñanza geográfica, al proponer el análisis de las temáticas y problemáticas comunitarias. Por ejemplo, debatir en el aula de clase con el propósito de educar ciudadanos cultos, sanos, creativos, críticos y con conciencia democrática. Así, la escuela podrá aportar opciones para renovar el cambio curricular y los procesos formativos de enseñanza y de aprendizaje.

Asimismo, la renovación pedagógica a partir del enfoque cualitativo, en el planteamiento de Martínez (2004), facilitará el desenvolvimiento de oportunidades didácticas para leer activamente la vida cotidiana en forma hermenéutica, escribir en forma razonada y argumentadamente, como también exponer ideas coherentes y construir el pensamiento crítico, entre otros aspectos. Eso supone avanzar dialécticamente de la transmisión de contenidos programáticos hacia la formación integral de los ciudadanos.

Se trata de proponer la integración curricular a partir de los fundamentos del enfoque cualitativo, como opción para renovar la geografía escolar más allá del positivismo pedagógico. En efecto, articular lo empírico, el saber escolar y los conceptos programáticos, activar la participación activa, la ejercitación de la observación analítica e interpretativa, la agitación del pensamiento reflexivo y la actitud hacia el cambio. Así, se podrá explicar críticamente la compleja época vivida.

\section{Consideraciones Finales}

En el ámbito del mundo contemporáneo, ante la reiterada exigencia de plantear la formación de ciudadanos, en correspondencia con la complicada, novedosa e interesante realidad socio-histórica contemporánea, se han formulado persistentes cuestionamientos al modelo educativo vigente en la práctica escolar cotidiana. En las abundantes referencias bibliográficas sobre la educación, la pedagogía y la didáctica, se pregona la apremiante necesidad de dar un viraje a los procesos formativos de enseñanza y de aprendizaje.

Sin embargo, en el cuestionamiento resulta poco citada la influencia de la ciencia positiva en la finalidad educativa, los diseños curriculares, los programas escolares y los procesos pedagógicos y didácticos especialmente. En la generalidad de los casos se menciona con énfasis el apremio a la aplicación de las estrategias didácticas, siempre con el signo innovador y de transformación del acto educante. Igualmente se hace hincapié en el uso de recursos didácticos novedosos con la posibilidad de mejorar la acción educativa. 
Lo llamativo de esta circunstancia es evadir el análisis sobre la persistencia de los contenidos referidos a los rasgos físico-naturales de la superficie terrestre, los aspectos demográficos y las actividades económicas. Son los conceptos tradicionalmente apreciados en la enseñanza geográfica; por cierto, propuestos en la geografía escolar decimonónica, con el propósito de conservar la objetividad, descartar la reflexión analítico-crítica y la manifestación de la subjetividad construida sobre el paisaje del lugar.

En efecto, se desvía la atención hacia la comprensión de la realidad geográfica vivida y persiste el afán de limitar el acto educante a transmitir contenidos librescos de sentido absoluto. Así, se desnaturaliza el apremio social de un modelo educativo orientado a estudiar la complejidad de la época; en especial, los inciertos, paradójicos e inesperados sucesos ambientales, geográficos y sociales. Por eso se justifica cuestionar la vigencia de los fundamentos pedagógicos del positivismo, como la base central de la acción educativa.

Con la orientación positiva del acto educante, se evita la posibilidad de asumir posturas interpretativas críticas, como la pretende la ciencia cualitativa. Significa que mientras el positivismo ejercita la reproducción conceptual, la opción cualitativa reivindica la participación y el activo protagonismo para familiarizarse con lo real y elaborar el conocimiento, como un constructo hermenéutico; es decir, implica involucrarse en la realidad, vivir la dificultad estudiada, conocer en la vivencia hacia la conciencia crítica.

Esta situación exige el fomento de procesos de enseñanza y de aprendizaje que faciliten a los estudiantes oportunidades de ejercitar en la exposición del sentido común; participen activa y reflexivamente en la indagación conducente a construir el conocimiento y echar las bases de la comprensión razonada básica y fundar un escenario democrático. De esta forma los ciudadanos podrán ejercer el derecho político en forma constructiva hacia el mejoramiento de su calidad de vida.

Con la ciencia cualitativa será posible otro acto educante más coherente con las necesidades de la sociedad, pues ayudará a entender la naturaleza del territorio habitado, como estar en condiciones de organizar su espacio geográfico en forma más humanizada. Eso conduce a proceder a introducir los fundamentos teóricos y metodológicos de la orientación cualitativa al aportar a la enseñanza de la geografía la posibilidad de intervenir protagónicamente la realidad comunitaria.

En esa dirección, con los conocimientos y prácticas del viejo paradigma y el joven paradigma, se podrá aminorar el notable desfase entre el aula, la escuela y la comunidad, al facilitar la confrontación con la realidad vivida, como permitir la construcción de verdades relativas, flexibles y donde predomine la apertura, la tolerancia y la visión de totalidad. En efecto, se impone desarrollar investigaciones para estudiar críticamente los eventos de la práctica escolar cotidiana, pues es allí no solo ocurre lo observado, sino también sus causas.

En las condiciones del mundo contemporáneo se debe asumir el desafío de democratizar la ciencia geográfica y su utilidad en la transformación social. El resultado pedagógico más significativo será, indudablemente, la existencia de una subjetividad más ágil, crítica y constructiva para entender racionalmente la compleja realidad y su efecto más analítico y protagónico en el comportamiento social. De esta forma, la alfabetización geográfica contribuirá con humanizar al ciudadano ante la compleja y adversa realidad vivida.

El salto desde el positivismo hacia la aplicación didáctica de los fundamentos teóricos y metodológicos del enfoque cualitativo representa un extraordinario avance en la inquietud por innovar científica y pedagógicamente la enseñanza de la geografía. Es avanzar desde la contemplación neutral hacia la interpretación hermenéutica de la 
realidad en que conocer se traduce en la formación vivencial de la conciencia crítica, como educar para comprender el mundo vivido desde una racionalidad popular y democrática.

\section{Referencias}

Aiello, M. (2005). Las prácticas de la enseñanza como objeto de estudio. Una propuesta de abordaje en la formación Docente. Revista Educere Año 9, N 30, 329-332.

Calle Carracedo, M (2012). La enseñanza de la geografía ante los nuevos desafíos ambientales, sociales y territoriales. Revista Educación Geográfica Digital, 33-52.

Calvo Ortega, F. (2009). La ciencia y la didáctica de la geografía: investigación geográfica y enseñanza escolar. Revista Cuestiones Pedagógicas. Nº 20, 269-282.

Camilloni, A. R. (2001). Los obstáculos epistemológicos en la enseñanza. Barcelona (España): Editorial Gedisa, S.A.

Capel, H. (1988). Filosofía y ciencia en la geografía contemporánea. Tercera Edición. Madrid: Editorial Barcanova, S.A.

De Zubiría, J. (2006). Los modelos pedagógicos contemporáneos. $2^{\mathrm{a}}$ edición. Bogotá: Cooperativa Editorial del Magisterio.

Dobson, A. (1997). Pensamiento político verde. Una nueva ideología para el siglo XXI. Barcelona (España): Ediciones Paidós Ibérica.

Ferriere, A. (1959). La escuela sobre la medida a la medida del maestro. Buenos Aires: Editorial Kapelusz, S. A.

Finocchio, S.; García, P.; Iaies, G: y Segal, A. (1998). Enseñar Ciencias Sociales. Buenos Aires: Editorial Troquel, S.A.

Gallego Badillo, R. y Pérez Miranda, R. (2003). El problema del cambio en las concepciones epistemológicas, pedagógicas y didácticas. Bogotá: Universidad Pedagógica Nacional

Graffe, J. E. (1990, agosto 03). Ciencias, espíritu y posmodernidad. Diario El Nacional, Caracas, p. 5-8.

Hernández G., A. M. (1996, diciembre 30). El error de pensar en el error. Diario El Globo, Caracas. p. 23.

Inga A., M. G. (2009). Importancia de la Investigación Cualitativa para la acción educativa: presentación de un modelo revistas. UNMSN. Investigación educativa Volumen. 13, No 24, 205-219.

Krygier, A. (2000, marzo 14). Pensamiento sistémico. Diario El Nacional, Caracas. p. A-4.

Mabel Briuoli, N. (2007). La construcción de la subjetividad. El impacto de las políticas Sociales. Revista HAOL, Núm. 13, 81-88.

Martínez M. M. (2004). Ciencia y arte en la metodología cualitativa. México: Editorial Trillas, S. A. de C.V.

Martínez M., M. (1999). La nueva ciencia. México: Editorial Trillas.

Martínez M., M. (2009). Epistemología y metodología cualitativa en las ciencias sociales. Editorial Trillas, Ciudad de México, México.

Martínez M., M. (2016). El conocimiento y la ciencia en el siglo XXI. Segunda Edición, México: Editorial Trillas.

Mejía, M. R. (2011). Pensar la educación y la pedagogía en el siglo XXI. Tunja, Boyacá, Universidad Pedagogía y Tecnológica de Colombia.

Perafán Echeverri, G. A. (2004). La epistemología del profesor sobre su propio conocimiento profesional. Bogotá: Universidad Pedagógica Nacional.

Plans, P. (1962). La enseñanza de la geografía en la escuela primaria. Revista Vida Escolar Año V. No 35-36-, 19-21.

Posner, G. J. (1998). Análisis de currículo. Bogotá: McGraw-Hill Interamericana, S. A. 
Ríos, P. (2004). La aventura de aprender. Ponencia en la Jornada sobre Paradigmas y procesos en educación. De la teoría a la práctica. U.P.E.L. Instituto Pedagógico Rural "Gervasio Rubio", Rubio, Venezuela.

Rivera J. F. y Cárdenas R., M. L. (2004). La globalización y la escuela. Revista Presente y Pasado. Año 9. Volumen 9, $\mathrm{N}^{\circ}$ 17, 187-193.

Santana P., J. M. (2005). Paradigmas historiográficos contemporáneos. Barquisimeto (Venezuela): Fundación Buría.

Santiago R., J. A. (2013). La práctica escolar cotidiana de la enseñanza geográfica como objeto de la investigación pedagógica. (Capítulo de un Libro). Barquisimeto: Universidad Pedagógica Experimental Libertador.

Santiago R., J.A. (2012). La cotidianidad contemporánea desde las teorías geográficas y la renovación de la enseñanza de la geografía. Revista Anekumene, Volumen 1. No 4, 8-22.

Santiago Rivera, J. A. (2016). La geografía descriptiva como obstáculo epistémico en la enseñanza de la geografía. Revista Nadir: Revista Electrónica Geografía Austral. Año 8, Nº 2, 01-14.

Santos, M. (2004). Por otra globalización. Del pensamiento único a la conciencia universal. Bogotá: Edición del Convenio Andrés Bello.

Villegas, M. M. (2001). La construcción del conocimiento y la subjetividad en el escenario del aula de clase. Revista de Pedagogía, Vol. XXII, Núm. 63, 133-144. 